\title{
The Energy Thoughts of Hu Jintao
}

\section{Guo-lian WANG ${ }^{1, a}$, Dong-sheng $\mathrm{YI}^{2, b}$}

\author{
Department of Ideological and Political Education, Huaiyin Institute of Technology, Huaian, 223003, \\ China \\ Humanities College, Huaiyin Institute of Technology, Huaian 223003, China \\ awglszb@163.com, byidongsheng91@163.com,
}

Keywords: Hu Jintao; Energy Issues; China's Thoughts

Abstract. Energy issues are what Hu Jintao highly values, that's why he develops his energy thoughts to be more systematic and comprehensive. To study Hu's energy thoughts leaves a practical significance on the progress of energy generation as well as consumption revolution.

\section{Introduction}

Basically speaking, Energy, as the foundation of humans' existence and development, is the fundamental material requirement of production and livelihood. It is the locomotive that pushes economy and society ahead and the strategic substance that plays an important role in national security. Out of the concern about energy issues, Hu Jintao has delivered a series of penetrating elaborations from different perspectives. These elaborations reflect the themes of the times, conform to the trend of development and adapt to national conditions, therefore they become the constituents of his relatively complete energy outlook.

\section{The Particularity of Energy Issues in China}

After entering the new age, fast economic growing follows the increasingly prominent imbalance between energy supply and demand and as a consequence, energy issues have stood in the way of national economic development. Severe ecological as well as environmental problem is caused by our coal-dominated energy structure, possible crisis in oil supply exists because of the constantly improved petroleum net import rate and oil price seesaws due to incessant geopolitical conflicts. Such all illustrate that energy security is outstanding in China's economic progress and relevant issues are urgent and thorny for Chinese government to be addressed.

Proceeding from China's concrete conditions and the features of development stages, Hu Jintao, with global perspective and his political and historical responsibilities to Chinese people as well as people from other countries, comprehensively expounds the strategic position of energy and has an in-depth knowledge on the importance and complexity of global energy security. In 2005, he pointed that energy and resources issues play a strategic role in our national economic and social development. In 2006, he emphasized that energy and resources are significant materials which are fundamental for humans' existence and evolution and important for our construction of a moderately prosperous society in all aspects and the promotion of socialist modernization. On July 17th, 2006, at the G8 Summit in St. Petersburg, Russia, Hu said that global energy security links to economic artery as well as people's livelihood, that's why it is vital to uphold world peace and stability and push forward a common development. On July 9th, 2008, at Leaders Meeting on Energy Security and Climate Change in Economic Powers in Toyako, Hokkaido, Japan, he stressed that with the rapid development of world economy, especially that of the industrialization, issues about global energy, environment and climate change have become increasingly prominent, leaving the world a common challenge.

\section{China's Thoughts and Strategies on Solving Energy Problems}

Energy is intertwined with various aspects, such as a country's economy, environment, climate, diplomacy, politics and so on. Any slight move in it may affect the situation as a whole. Therefore 
each country's concrete thoughts and strategies to address energy problems play an guidance role. According to the current condition and characteristic of our energy and in line with the peaceful, developmental and cooperative themes of the times, Hu Jintao emanated China's thoughts and strategies on solving energy problems.

Adhering to open, mutually beneficial development philosophy, Hu gives us China's thoughts on dealing with energy security. Energy issues are global. Since the beginning of the industrial revolution, history has shown that issue of global energy security has long been existed. It is a sensitive nerve for many countries. On July $17^{\text {th }}$, 2006, at Dialogue Between G8 and Leaders in Developing Countries, he proposed China's stand on global energy security, that is to guarantee global energy security, we are supposed to establish and implement a new energy concept of win-win cooperation, diversified development and collaborative guarantee. Therefore, he came up with an idea that countries are supposed to make efforts together in the following three aspects: strengthening the mutually beneficial cooperation in exploring and utilizing energy, establishing a promotion system of the advanced energy technology research and maintaining a sound political environment for energy security and stability. By the way, he emphasized that countries should cope with disputes and contradictions by dint of dialogue and consultation rather than politicize energy issues or appeal to arms. All of these show us that China's thoughts on global energy security are thoughts of political wisdom and embodiment of building a harmonious world. It is China's thoughts that manifest the trend of development and that put the philosophy of sustainable development into energy field. What's more, China's thoughts also leave us a dialectical way of thinking as well as an example of global management in energy field.

With candid and practical attitude, Hu yields a highly concise illustration about China's current content of energy strategy. Energy issues are prominent in China. Since the implementation of reform and opening up policy, China's economy has zoomed up and people's livelihood has improved. As a result, energy demand has raised substantially. Some people, with ulterior motives, seize the chance and spread "Chinese energy threat", saying that China is the predator of global energy and questioning that who will drive China. Being confronted with domestic energy difficulty and international clamour, Hu Jintao, on July $17^{\text {th }}, 2006$, at Dialogue Between G8 and Leaders in Developing Countries, embodies a candid and practical attitude and gives us a highly concise illustration about China's current content of energy strategy, that is adhering to the principle of saving first, China will take national condition as standpoint, pursuing diversified development and protecting environment. Through international cooperation, China will spare no effort to build a stable, economic and clean energy supply system. From this, it is clear to see that China regards energy conservation as its basic national policy and sticks to explore energy while saving it. Based on current national conditions, China will develop energy under the principle of equality, reciprocity and win-win cooperation and will uphold world energy security and stability as well. At the same time, China will embrace the goal of building a resource-saving and environmentally friendly society so as to make a coordinated development between energy and environment.

With high degree of historical mission and intense sense of time duty, Hu proposes the development of renewable energy sources and clean energy. The development and utilization of energy is key to solving energy problems. The use of energy has changed all the time, from firewood to coal and then to oil and natural gas. Now it is changing from oil and gas to new energy. According to the above-mentioned transitions, we can find that energy technology has gone through a corresponding transition, from drilling wood to make fire to utilizing steam engine, electric power and atomic energy. However, industrialization leads to a surge in fossil energy consumption, which causes a continuously deteriorated environment, especially the global climate change brought by green house gas emissions. People are looking forward a great revolution in energy use, that is to change from exploiting fossil energy to creating renewable one. Hu Jintao highly values the cause of renewable energy. In November 2005, he made a speech at Beijing International Renewable Energy Conference. In it, he pointed that renewable energy is abundant, clean. To intensify the development and utilization of renewable energy is essential for us to face increasingly severe energy and environment problems and it is also a must for people to realize a sustainable development. On 
September 22th, 2009, he made a speech with the title of Work Together To Address Climate Change. He proposed that China will adopt further step to develop economy and society while dealing with climate change. We will spare no effort to let non-fossil energy have about $15 \%$ in primary energy consumption by 2020. On behalf of Chinese government, this is Hu's promise to the world. Shortly after, during his visit in Shandong Province, he made a special trip to Datang dongying wind power project and made an emphasis that renewable energy enterprises are supposed to grasp opportunity, focus on world industry cutting edge and tackle difficulties in scientific research. They should make constant progress in core and key technology so as to occupy the high ground in future development. $\mathrm{Hu}$ Jintao, with the responsibility to Chinese people as well as the people from other countries, has an in-depth knowledge on necessity and strategic position of renewable energy to people's sustainable development and the importance and urgency of it to copying with climate change. Furthermore, having seen that the world technological revolution is escalating, he leaves us a scientific revelation that the development and utilization of renewable energy is guiding and significant in a new round energy revolution.

Taking the responsibility to his nation, people as well as future generations, Hu stresses the significance of saving energy and resources many times and proposes a concrete strategy of how to make it. Energy and resources reserves are limited, that's why we put a new premium on energy conservation. Non-renewable energy resource is finite in today's world, we should keep the energy crisis bell ringing in our mind. China, as the biggest developing country in the world, produces energy resource on one hand and consumes on the other hand. It lacks energy resource and wastes it at the same time. It is the finiteness of the world non-renewable energy and the dual nature of our energy condition that determine the strategic position of energy conservation. At the $23^{\text {rd }}$ collective study of the political bureau of the central committee of the CPC, 2005, he pointed that to deal with our own energy problem, saving more and consuming less should be equally valued. Furthermore, we should carry a new way of saving energy resources. It is characteristic of high technology content, good economic returns, low resource consumption, little environmental pollution and full play to human resource. This is the requirement of scientific outlook on development and an important part in our national sustainable development. During this group learning, he also proposed eight concrete tactics of energy conservation. They base on current condition and focus on the future development. Afterwards, at various occasions, he repeated that energy conservation can never be important and reduction should be the starting point when copying with climate change. It is clear to see that $\mathrm{Hu}$ Jintao takes the responsibility to his nation, people and future generations. He knows that energy conservation is not an makeshift but a long-term strategy, which should be put priority and be regarded as a very complex engineering.

Hu Jintao's thoughts of energy resource is a guidance for our energy cause to be sound, stable and sustainable. It is a element of scientific outlook on development and is helpful to face global climate change. Since the Eighteenth National Congress of the Communist Party of China has convened, the CPC Central Committee with Xi Jinping as general secretary has embraced and enriched Hu's thoughts, that's why we advocates to promote energy consumption revolution. We believe that through efforts made by generations, Our energy cause is sure to find a balance between environment, development, politics on one hand and diplomacy, economy and resources on the other and finally to achieve a comprehensive,sound and sustainable development in ecology, livelihood and production.

\section{Acknowledgements}

This study is financially supported by the Foundation of Philosophy and Social Science from Department of Education, Jiangsu Province (2010SJD720001).

\section{References}

[1] Hu Jintao,: a comprehensive energy resources work, priority to save energy resources, http://news.xinhuanet.com/newscenter/2005-06/28/content_3148777.htm. (In Chinese) 
[2]Thirty-seventh collective study of the CPC Central committee, http://news.sina.com.cn/c/2006-12-27/102110873737s.shtml. (In Chinese)

[3] Hu jintao at the group of eight's speech dialogue meeting with the leaders of developing countries, http://news.xinhuanet.com/newscenter/2006-07/17/content_4845662.htm. (In Chinese)

[4] Hu jintao, in economic power energy security and climate change leader's speech at the meeting, http://news.xinhuanet.com/newscenter/2008-07/10/content_8519929.htm. (In Chinese)

[5] Hu Jintao gave a speech at the 2005 Beijing international renewable energy conference, http://www.gov.cn/node_11140/2006-04/22/content_261048.htm. (In Chinese)

[6] Hu Jintao. To address climate change challenges, http://news.xinhuanet.com/world/2009-09/23/content_12098929.htm. (In Chinese)

[7] Hu Jintao expounded China's principled position on the issue of climate change, http://news.xinhuanet.com/newscenter/2008-07/09/content_8516515.htm. (In Chinese) 